\title{
Evaluation of satisfaction and complications in patients with existing complete dentures
}

\author{
Hakan Bilhan, Onur Geckili, Selen Ergin, Ozge Erdogan, and Gokcen Ates
}

\author{
Department of Prosthodontics, Faculty of Dentistry, Istanbul University, Istanbul, Turkey
}

(Received July 17, 2012; Accepted December 20, 2012)

\begin{abstract}
The aim of this clinical trial was to assess satisfaction, as well as the frequency and type of prosthetic complications in terms of several variables, in patients with complete dentures that had been supplied at private clinics. The study subjects were 64 patients with a mean age of 63.48 years wearing complete dentures provided at private clinics, and requesting new ones. The degree of patient satisfaction with their dentures was assessed, as well as complications and parameters related to the dentures such as the accuracy of vertical dimensions and centric relation, arrangement and possible malposition of the artificial teeth, and the border length of the denture bases. The most common complication was loss of retention $(85.9 \%)$, followed by ulceration (44.2\%). Mandibular dentures with long vestibular borders showed a significantly higher incidence of epulis fissuratum $(P=0.017)$, and denture-related sore spots influenced patients' speech ability $(P=0.023)$. Routine recalls seem to be important for wearers of complete dentures, as several insidious complications may develop and cause damage to the dentures as well as the patients' oral tissues.
\end{abstract}

(J Oral Sci 55, 29-37, 2013)

Keywords: complete denture; complication; vertical dimension; centric relation; patient satisfaction.

\section{Introduction}

Since tooth loss can impair oral function, esthetics and phonation, prosthodontics are important for restoration

Correspondence to Dr. Onur Geckili, Department of Prosthodontics, Faculty of Dentistry, Istanbul University, 34093s Capa, Istanbul, Turkey

Fax:+90-212-5253585 E-mail: geckili@istanbul.edu.tr of the dentition. The increase in the prosthetic restorations of elderly individuals due to longer life expectancy means that the demand for prosthodontic treatment will increase in the next few decades due to a higher frequency of edentulism, even in countries with a high standard of dental health care (1). Reports issued by the World Health Organization have indicated that the incidence of edentulism in individuals older than 65 years was $58 \%$ in Canada in 1993, 36\% in Finland in 1997, and 46\% in the United Kingdom in 1998 (2). In 1998 it was reported that $13 \%$ of all adults in the UK were edentate, and that the condition was strongly correlated with age (3).

As people increasingly wish their natural tooth function to continue rather than use dentures, a degree of prejudice against dentures appears to exist. This appears to have been confirmed by a study in 1998, which found that over $60 \%$ of people who relied only on natural teeth stated that they would be very upset if their oral function had to rely on complete dentures (4). This prejudice becomes more marked as people get older. One possible explanation is that the longer a person has managed to avoid dentures, the more upsetting it becomes when the battle is finally lost. This hardening of opinion becomes especially significant when linked to the fact that, in the future, most people receiving complete dentures will inevitably be elderly. It is important for dentists to be aware of this situation, as it can have a significant impact on how patients respond to receiving complete dentures when the time comes. With the mass of information that has accumulated over the last 30 years, it has become possible to predict future trends with reasonable confidence. If the current trends continue, it is calculated that by 2018 only $5 \%$ of the adult population will be edentate (5). The clear trend is for a delay in the onset of tooth loss, but since life expectancy is increasing, treatment for edentulism will still be necessary eventually, as individuals get older. 
Treatment of edentulism with complete dentures is still employed widely because of its relative inexpensiveness and simplicity. However, complete dentures may be associated with various complications. Much research has been undertaken in an effort to explain why some patients have more difficulty than others in wearing complete dentures successfully. The technical quality of dentures is certainly important, but medical and psychological factors are also considered to be contributory $(6,7)$. Although it is known that older individuals take longer to adapt to new dentures, various questionnaires, interviews and personality assessments have been unable to identify any particular factors that may predict a patient's dissatisfaction with dentures. Insufficient studies have investigated aspects such as vertical dimension, centric relation, position of the artificial teeth relative to the denture base and underlying tissues and the borders of dentures to provide information about general trends in the quality of dentures provided in general practice. However, textbooks have pointed out the importance of the tooth setup for achieving denture stability $(8,9)$. A few audit studies of dentures constructed in general dental laboratories have shown that the main technical faults can be summarized as excessive reduction of denture borders and large changes in vertical dimensions $(10,11)$. If the occlusal vertical dimension of dentures is established too high, the patient may complain of continuous clattering of the teeth or generalized pain that increases during the day. Additionally, during mastication, the patient may feel a lack of sufficient space for food. Centric relation and centric occlusion are known to be important for denture comfort.

Overextension of denture borders can cause ulceration and pain, and may impair retention. Retention and stability are also negatively influenced by short denture borders. Extension of the posterior borders can result in excessive pressure, swallowing difficulties and even sore throat. Short and long borders are often caused by inadequate molding of the periphery at the impression stage.

Many textbooks have pointed out the importance of adaptation of the denture base to the underlying tissues, accurate setup of the artificial teeth, and establishment of a proper centric relation and vertical dimension for maintaining the retention and stability of complete dentures (12). It is also likely that the aforementioned factors would influence the appearance of dentures, their associated complications, and patient satisfaction. However, as Dorner et al. (2) have commented, there is a lack of information on the performance of removable dentures.

A professional evaluation of complete denture quality may not always agree with the personal opinion of the patient. The parameters related to this issue have varied in the available literature. Weak or reasonably significant correlations have been found in some studies (13-18), whereas other studies have failed to find any correlation (19-22).

Since prosthodontic as well as surgical treatment can be performed to improve patient satisfaction, oral health-related quality of life (OHRQoL) must be influenced by the quality of the prosthetic treatment (23-29). In a previous study conducted in the United States that assessed the quality of 1306 removable partial dentures (RPDs), 65\% of the RPDs were found to have various types of defects (30), indicating poor quality. Although a very recent study has reported that the quality of removable dentures had a minimal effect on OHRQoL (31), another study pointed out that improving RPD quality could have a substantial effect on the oral health of the population, assuming a causal association between denture quality and OHRQoL (32).

The present clinical trial was designed to gather data about patient satisfaction and complications related to complete dentures provided at private clinics, and to evaluate their possible relation with several denturerelated parameters.

\section{Patient selection \\ Materials and Methods}

Edentulous patients presenting at a University Clinic during a 3-month period for treatment with new complete dentures were observed and interviewed. The patient inclusion criteria were being edentulous, having worn complete dentures provided by private clinics for at least 3 years, and ability to read and sign the informed consent form provided. This study was approved by the institutional review board (form number 2011/15-401).

\section{Examination procedures}

Using standardized forms, each patient's age, gender, and presence of prosthetic complications were recorded.

The patients and dentures were examined by two qualified prosthodontists who were blinded to the study protocol, and the following prosthetic complications were recorded:

1. Loss of retention

2. Ulceration

3. Denture base fracture

4. Loss or fracture of artificial teeth

5. Denture stomatitis

6. Inflammatory papillary hyperplasia

7. Epulis fissuratum

The positions of artificial teeth were assessed for two 
groups - incisors and molars - in both the maxilla and mandible. The positions of artificial teeth were also assessed, and scored as regular, vestibular position or lingual. We then analyzed the relationship between the positions of artificial teeth, patient satisfaction, and the frequency of complications.

Vertical dimensions of the examined dentures were scored as normal, high or low, while the centric relations were scored as correct or incorrect. For establishment of vertical dimensions, the phonetic method was used, as outlined by Silverman (33). Centric relations were established using the three-finger chin-point guidance method (34).

The existing denture borders were graded as follows, and their relationships with patient satisfaction and the frequency of complications were analyzed:

a. Maxillary post-dam area: long, normal or short

b. Maxillary tuber area: long, normal or short

c. Mandibular distolingual and retromolar pad area: long, normal or short

d. Mandibular buccal pouch: long, normal or short

e. Vestibular borders of the maxillary and mandibular denture bases: long, normal or short

Each patient used a visual analog scale (VAS) to express satisfaction with esthetics, chewing ability and phonetics when fitted with the prosthesis, and this was used to analyze patient satisfaction in terms of centric relation, vertical dimension, and denture border lengths, the condition of the dentures and the position of artificial teeth.

Any complications were evaluated with respect to vertical dimension or centric relation. The relationship between complications and patient satisfaction was also analyzed.

Denture conditions were assessed for hygiene (good/ bad), artificial tooth wear (present/absent) and coloring (present/absent). The relationships of denture conditions to VAS scores and complications were also analyzed.

The potential effects of various parameters on denture complications and patient satisfaction were subjected to statistical analysis using Microsoft Excel 2007 (Microsoft, Redmond, WA, USA) and the SAS statistical software package, version 8.2 (SAS Institute, Cary, NC, USA). In addition to descriptive statistics (means and standard deviations), quantitative data were compared using the Kruskal-Wallis test, whereas Mann-Whitney $U$ test was used for comparison of non-parametric data. Comparison of qualitative data was performed using chi-squared test. The results were assessed at the 95\% confidence interval at a significance level of $P<0.05$.
Table 1 The positions of artificial teeth

\begin{tabular}{llrr}
\hline & Positions & $n$ & $\%$ \\
\hline Maxillary incisors & Vestibular position & 8 & 12.5 \\
& Regular & 46 & 71.8 \\
& Lingual position & 10 & 15.6 \\
Maxillary molars & Vestibular position & 17 & 26.5 \\
& Regular & 46 & 71.8 \\
& Lingual position & 1 & 1.5 \\
Mandibular incisors & Vestibular position & 9 & 14.0 \\
& Regular & 52 & 81.2 \\
& Lingual position & 3 & 4.6 \\
Mandibular molars & Vestibular position & 3 & 4.6 \\
& Regular & 60 & 93.7 \\
& Lingual position & 1 & 1.5 \\
\hline
\end{tabular}

Table 2 The parameters evaluated for vertical dimension, centric relation and denture condition.

\begin{tabular}{llrr}
\hline & & $n$ & $\%$ \\
\hline Vertical dimension & Normal & 17 & 26.5 \\
& High & 2 & 3.1 \\
& Low & 45 & 70.3 \\
Centric relation & Right & 41 & 64.0 \\
& Wrong & 23 & 35.9 \\
Denture condition & Bad Hygiene & 35 & 54.6 \\
& Wear & 31 & 48.4 \\
& Coloring & 42 & 65.6 \\
\hline
\end{tabular}

Table 3 Esthetics, chewing ability and phonetic VAS scores

\begin{tabular}{lccc}
\hline Patient satisfaction(VAS) & Min-Max & Mean \pm SD & Median \\
\hline Esthetics & $0-100$ & $64.27 \pm 31.80$ & 72.5 \\
Chewing ability & $0-100$ & $57.73 \pm 32.89$ & 50 \\
Phonetic & $0-100$ & $77.27 \pm 29.04$ & 90 \\
\hline
\end{tabular}

\section{Results}

Sixty-four patients (mean age $63.48 \pm 8.42$ years; 39 females $(60.9 \%)$ and 25 males $(39.1 \%)$ ) fulfilling the above-mentioned criteria were included in the present study.

The frequencies of complications in terms of patient number were:

$85.9 \%$ - Loss of retention

$44.2 \%$ - Ulceration

$31.4 \%$ - Loss or fracture of artificial teeth

$27.5 \%$ - Denture base fracture

$8.3 \%$ - Denture stomatitis (Newton Types 1 and 2)

$4.2 \%$ - Epulis fissuratum

$1.2 \%$ - Inflammatory papillary hyperplasia

The positions of the artificial teeth for both maxillary and mandibular dentures are classified in Table 1.

The scored parameters for vertical dimensions, centric relations and denture conditions are presented in Table 2 , whereas the satisfaction scores including esthetics, chewing and phonetic abilities are presented in Table 3 . 
Table 4 Effects of mandibular denture vestibular borders on complications

\begin{tabular}{|c|c|c|c|c|}
\hline \multirow[b]{2}{*}{ Complication Type } & \multicolumn{3}{|c|}{ Vestibular borders mandibular denture } & \multirow[b]{2}{*}{$P$} \\
\hline & $\begin{array}{c}\text { Long }(n=10) \\
n(\%)\end{array}$ & $\begin{array}{c}\text { Short }(n=34) \\
n(\%)\end{array}$ & $\begin{array}{c}\text { Normal }(n=20) \\
n(\%)\end{array}$ & \\
\hline Ulcerations & $4(40.0)$ & $20(58.8)$ & $10(50.0)$ & 0.546 \\
\hline Loss of retention & $9(90.0)$ & $31(91.2)$ & $15(75.0)$ & 0.236 \\
\hline Lost or fractured artificial teeth & $2(20.0)$ & $10(29.4)$ & $5(25.0)$ & 0.823 \\
\hline Denture base fracture & $1(10.0)$ & $11(32.4)$ & $8(40.0)$ & 0.243 \\
\hline Denture stomatitis & $1(10.0)$ & $2(5.9)$ & $3(15.0)$ & 0.539 \\
\hline Epulis fissuratum & $3(30.0)$ & $1(2.9)$ & $1(5.0)$ & $0.017^{*}$ \\
\hline Inflammatory papillary hyperplasia & $0(0.0)$ & $2(5.9)$ & $0(0.0)$ & 0.402 \\
\hline
\end{tabular}

Chi-square test $* P<0.05$

Table 5 Relationship between complications and VAS scores

\begin{tabular}{|c|c|c|c|c|c|c|c|}
\hline Complication type & & Esthetic VAS scores & $P$ & Chewing ability VAS scores & $P$ & Phonetic VAS scores & $P$ \\
\hline Ulceration & $\begin{array}{l}+ \\
-\end{array}$ & $\begin{array}{l}59.12 \pm 33.52 \\
70.10 \pm 29.19\end{array}$ & 0.193 & $\begin{array}{l}53.09 \pm 32.17 \\
63.00 \pm 33.44\end{array}$ & 0.197 & $\begin{array}{l}69.85 \pm 32.37 \\
85.67 \pm 22.43\end{array}$ & $0.023 *$ \\
\hline Loss of retention & $\begin{array}{l}+ \\
-\end{array}$ & $\begin{array}{l}69.32 \pm 31.59 \\
61.03 \pm 31.92\end{array}$ & 0.177 & $\begin{array}{l}55.00 \pm 30.17 \\
58.98 \pm 34.31\end{array}$ & 0.549 & $\begin{array}{l}74.75 \pm 27.79 \\
78.41 \pm 29.84\end{array}$ & 0.404 \\
\hline $\begin{array}{l}\text { Lost or fractured artificial } \\
\text { teeth }\end{array}$ & $\begin{array}{l}+ \\
-\end{array}$ & $\begin{array}{l}64.12 \pm 26.29 \\
64.32 \pm 33.83\end{array}$ & 0.582 & $\begin{array}{l}66.18 \pm 27.59 \\
54.68 \pm 34.36\end{array}$ & 0.238 & $\begin{array}{l}82.35 \pm 24.69 \\
75.43 \pm 30.50\end{array}$ & 0.777 \\
\hline Denture base fracture & $\begin{array}{l}+ \\
-\end{array}$ & $\begin{array}{l}61.00 \pm 31.02 \\
65.75 \pm 32.39\end{array}$ & 0.448 & $\begin{array}{l}48.33 \pm 27.87 \\
58.71 \pm 33.42\end{array}$ & 0.416 & $\begin{aligned} 100.00 & \pm 00.00 \\
74.91 & \pm 29.54\end{aligned}$ & 0.007 \\
\hline Denture stomatitis & $\begin{array}{l}+ \\
-\end{array}$ & $\begin{array}{l}55.00 \pm 36.19 \\
65.22 \pm 31.51\end{array}$ & 0.487 & $\begin{array}{l}64.20 \pm 29.71 \\
53.59 \pm 34.51\end{array}$ & 0.350 & $\begin{array}{l}83.80 \pm 19.16 \\
73.08 \pm 33.47\end{array}$ & 0.833 \\
\hline Epulis fissuratum & $\begin{array}{l}+ \\
-\end{array}$ & $\begin{array}{l}74.50 \pm 28.30 \\
63.58 \pm 32.12\end{array}$ & 0.801 & $\begin{array}{l}65.00 \pm 31.09 \\
57.25 \pm 33.20\end{array}$ & 0.623 & $\begin{array}{l}57.50 \pm 30.96 \\
78.58 \pm 28.70\end{array}$ & 0.248 \\
\hline $\begin{array}{l}\text { Inflammatory papillary } \\
\text { hyperplasia }\end{array}$ & $\begin{array}{l}+ \\
-\end{array}$ & $\begin{array}{l}25.00 \pm 35.36 \\
65.53 \pm 31.17\end{array}$ & 0.103 & $\begin{array}{l}50.00 \pm 00.00 \\
57.98 \pm 33.39\end{array}$ & 0.770 & $\begin{array}{r}100.00 \pm 00.00 \\
76.53 \pm 29.22\end{array}$ & 0.133 \\
\hline
\end{tabular}

Mann Whitney $U$ test $* P<0.05$

Table 6 Relationship between denture conditions and VAS scores

\begin{tabular}{|c|c|c|c|c|}
\hline & & $\begin{array}{l}\text { Esthetic VAS scores } \\
\text { Mean } \pm \text { SD (Median) }\end{array}$ & $\begin{array}{c}\text { Chewing ability VAS scores } \\
\text { Mean } \pm \mathrm{SD} \text { (Median) }\end{array}$ & $\begin{array}{l}\text { Phonetic VAS scores } \\
\text { Mean } \pm \text { SD (Median) }\end{array}$ \\
\hline Hygiene & $\begin{array}{l}\text { Good } \\
\text { Bad } \\
P\end{array}$ & $\begin{array}{c}64.66 \pm 31.54(75) \\
63.94 \pm 32.47(70) \\
1.000\end{array}$ & $\begin{array}{c}60.86 \pm 31.48(65) \\
55.14 \pm 34.25(50) \\
0.536\end{array}$ & $\begin{array}{c}72.41 \pm 30.49(85) \\
81.29 \pm 27.58(95) \\
0.154\end{array}$ \\
\hline Wear & $\begin{array}{l}\text { Present } \\
\text { Absent } \\
P\end{array}$ & $\begin{array}{c}65.26 \pm 31.02(80) \\
63.33 \pm 32.97(70) \\
0.876\end{array}$ & $\begin{array}{c}59.68 \pm 34.49(60) \\
55.91 \pm 31.73(50) \\
0.597\end{array}$ & $\begin{aligned} & 79.35 \pm 28.72(90) \\
& 75.30 \pm 29.66(85) \\
& 0.495\end{aligned}$ \\
\hline Coloring & $\begin{array}{l}\text { Present } \\
\text { Absent } \\
P\end{array}$ & $\begin{aligned} & 62.93 \pm 31.86(70) \\
& 66.82 \pm 32.28(80) \\
& 0.555\end{aligned}$ & $\begin{array}{c}55.95 \pm 34.08(50) \\
61.14 \pm 30.97(62.5) \\
0.623\end{array}$ & $\begin{array}{c}78.69 \pm 29.26(90) \\
74.55 \pm 29.11(82.5) \\
0.379\end{array}$ \\
\hline
\end{tabular}

Mann Whitney $U$ test

After evaluation of the positions of artificial teeth, no significant relationship was detected $(P>0.05)$ with patient satisfaction or the frequency of complications $(P$ $>0.05$ ).

With regard to the border extensions, there was a statistically significant relationship between the vestibular border length of mandibular dentures and the occurrence of epulis fissuratum. Mandibular dentures with long vestibular borders showed a significantly higher incidence of epulis fissuratum $(P=0.017$; Table 4). Maxillary and mandibular denture borders did not influence the incidence rate of other complications $(P>$ $0.05)$.

Evaluation of the relationship between denture border extensions and patient satisfaction revealed no significance $(P>0.05)$; there was also no significant 
relationship between vertical dimensions or centric relation and the incidence of complications or VAS scores $(P>0.05)$.

In terms of VAS scores, a significant relationship was found between the occurrence of ulceration and phonetic scores; patients with ulceration showed significantly lower phonetic VAS scores $(P=0.023$; Table 5$)$. No significant relationship was found between VAS scores and the occurrence of any other type of complication $(P$ $>0.05$; Table 5).

No significant relationship was found between the condition of the dentures and the incidence of denture stomatitis $(P>0.05)$. Additionally, denture condition did not influence the VAS scores $(P>0.05$; Table 6$)$.

\section{Discussion}

Most edentulous individuals over the age of 65 years are wearing dentures that are more than 10 years old, and as a result, mucosal changes are present in $44-63 \%$ of cases. The need for treatment, based on clinical judgment, suggests that $40 \%$ of 5 -year-old dentures and $80 \%$ of 10-year-old dentures should be replaced (35). Elderly people are likely to consider that treatment is required if they experience pain, difficulty in chewing, or a deterioration of oral appearance if existing dentures have been broken or lost.

The incidence of insufficient retention or instability of mandibular complete dentures increases with time due to the influence of accelerated residual bone resorption, and decreased chewing ability is the main complaint reported by patients $(15,16)$. In addition, any substantial pain and lack of patients' ability to communicate may result in psychosocial problems. The level of patient satisfaction can be evaluated using different questionnaires such as the VAS or OHQoL. A common problem with OHQoL surveys is failure of participants to complete all sections of the questionnaires or interview, which subsequently affects the overall impact score (36). Furthermore, a validated Turkish version of the OHIP-EDENT form, which was created for edentulous subjects, was not available at the time of the present study. Therefore, although OHQoL could not be assessed, patient satisfaction was evaluated using VAS forms, which created no difficulties for the patients.

Since the complete dentures prepared at the University Clinic, where the present study was carried out, were fabricated according to the same principles and quality, the studied patients were chosen from among individuals who had been treated at different private clinics in order to obtain a heterogeneous cluster.

In the present study, the most frequently encountered complication was loss of retention (85.9\%), followed by mucosal irritation (44.2\%), in accordance with the results of previous studies $(7,37)$. The reason for the high prevalence of retention loss and mucosal irritation may have been ongoing bone atrophy. Such atrophy occurs not only on the surface, but also involves height loss of the alveolar crest. Dentures tend to have long border extensions that have to be reformed by a relining procedure, since impaired adaptation of the denture base can cause ulceration and loss of retention $(38,39)$. Both complications may decrease patient satisfaction. Additionally, iatrogenic factors may be involved. An experienced clinician can differentiate between iatrogenic and atrophy-based overextension of denture borders. Typical iatrogenic overextension during impression-taking for mandibular dentures involves the retromylohyoid rims and masseter region, and buccal frenulae in both the mandibular and maxillary denture bases. On the other hand, the post-dam of the dentures tends to be rather too short, seriously affecting the retention of maxillary complete dentures. It is not possible to maintain a close approximation between the border of a denture and the mucosal reflection in the sulcus at all times because the depth of the sulcus varies during function. The denture has to be constructed so that the border conforms to the shallowest point that the sulcus reflection reaches during normal function. This means that for some of the time when the patient is at rest, the denture will be slightly underextended $(1,5)$. The results of the present study showed that ulceration caused dissatisfaction and difficulties while speaking. However, no relationship was detected between VAS scores and any other type of complication. It should be remembered that most of the patients were dissatisfied with their dentures and had come to the University Clinic for denture replacement. Therefore it may not be appropriate to draw definitive conclusions about patient satisfaction from the present population. However, it is still important that the lower degree of satisfaction with speech due to the presence of ulceration was a prominent feature of this patient group. Pain may have restricted tongue movement, and thus patients were dissatisfied with their speaking ability.

An investigation into the size of the problem in the UK reported that the National Health Service spends £7 million each year on denture repairs. This figure did not take into account the cost of repairs undertaken privately outside that government-financed scheme. The rate of fracture of removable polymer-based dentures has been reported to be as high as 68\% (40-42). Midline fractures appear to be one of the most common problems in maxillary complete dentures $(42,43)$. Midline fracture of a 
complete upper denture accounts for $29 \%$ of all repair work in dental laboratories, while tooth debonding from complete dentures accounts for $33 \%$ (44). Midline fracture of an acrylic denture may occasionally result from careless handling by the patient; for example, accidental dropping of the denture while cleaning can cause an impact fracture. Characteristically, however, midline fracture is due to fatigue of the acrylic resin produced by repeated flexing of the denture by forces too small to fracture it directly. Failure of the denture base is due to the progressive growth of a crack originating from a point on the surface, where an abrupt change in the surface profile causes a localized concentration of stress many times that applied to the bulk of the denture. The crack often starts palatally to the upper central incisors, grows slowly at first, but then undergoes an enormously increased rate of growth just before the denture fractures. A failure of this type most commonly occurs in dentures that are about 3 years old (45). Dentures tend to be subject of a seesaw effect around the hard palatal midline, when alveolar crest resorption occurs and the dentures are not relined. Whenever possible, the cause(s) of the fracture must be identified before the denture is repaired or replaced. Unless this is done and the cause corrected, the denture is likely to fracture again within a short period of time.

Debonding of teeth may occur due to trauma as well as a weak bond between a tooth and the denture base due to factors such as residual wax on the surface or crosslinked teeth that are incompatible with the particular denture base polymer, preventing effective chemical union and the production of an acceptable interwoven polymer network $(46,47)$. Considering both of these complications, the present study revealed that $27.5 \%$ of the patients suffered from denture fractures and $31.4 \%$ showed loss of artificial teeth, representing considerably high incidences.

The basic considerations when establishing correct occlusion for complete dentures are ensuring that the occluding rows of artificial teeth will provide optimum chewing efficiency, functional stability of the prosthesis, and comfort during chewing without exerting injurious forces on the denture-bearing tissues or adversely affecting esthetics or phonetics. It is assumed that tipping, sliding or heavy horizontal forces during the function of dentures will accelerate resorption of the effected ridge site. Therefore the setup of the teeth in complete dentures has been reported to play a key role in minimizing the tipping and sliding movements when chewing forces are applied (48). The importance of minimizing the nonphysiologic effects of occlusal forces by arranging the position of artificial teeth within the action zone of the tongue, cheeks and lips has also been emphasized (48). The bucco-lingual position of the mandibular posterior teeth and the posterior arch form are determined anteriorly by the position of the canine and posteriorly by the shape of the basal seat and the location of the retromolar pads (49). A line that extends from the tip of the canine to the middle of the retromolar pad will help determine the bucco-lingual positioning of the teeth. The posterior teeth are positioned in such a way that they are properly related to the bone that supports them and to the soft tissues in contact with their facial and lingual surfaces. Excessive lingual positioning of the posterior teeth will crowd the tongue. Conversely, excessive buccal positioning will destabilize the lower denture. The position of the anterior teeth is also very critical. Setting the teeth buccally will disturb the stability of the dentures, whereas lingual placement will diminish lip support, which is important for an esthetic outcome. For these reasons, the bucco-lingual positions of the anterior and posterior artificial teeth were scored in the present study, and their effects on complication rates and satisfaction were evaluated. However, the results showed that the positions of artificial teeth had no influence on either parameter. It should be pointed out that in most cases the positions of artificial teeth were scored as regular in the present study (Table 1), which might have explained the lack of any such influence. If more errors of tooth positions had been detected, the results could have been different, as Brunello and Mandikos (7) found in their study.

Additionally, the establishment of multilocal autonomous stabilizing contacts is important. The occlusal scheme and the tooth forms that will influence chewing efficiency (49) deteriorate over time due to occlusal wear. For this reason, in the present study the level of wear was recorded for each denture and its effect on patient satisfaction was evaluated. The results showed that occlusal wear did not influence the satisfaction scores. The reason for this result may have been the quality of the artificial teeth, because the vast majority of the dentures showed advanced wear. Low-quality artificial teeth are softer, and thus tend to grind and wear more easily. Since this wear proceeds slowly, patients have sufficient time to adapt, and their satisfaction is not affected.

The denture base is also an important factor influencing patient comfort. It should not mechanically traumatize the mucosa, or interfere with the normal function of the tongue, lips and cheeks, thus impairing the retention of the denture, and should not interfere with esthetics or speech $(1,48)$. An overbulked denture base may make it difficult for the cheek muscles to position the food bolus between the teeth, and interfere with lip movement during speech 
(48). Denture retention is a major requirement for patient satisfaction. The border extensions of dentures, which play a key role in retention (48), are determined mainly by the clinicians who are responsible for obtaining a good impression. Due to the influence of muscles and the compressibility of the mucosa, there will always be a certain amount of denture movement. Continuous reduction in the height of the alveolar ridges over a period of 25 years has been observed. There appears to be a marked reduction in the first year of denture use, and in the ensuing few years there is continuous loss averaging $1 \mathrm{~mm}$ per year. Over time, the loss in height of the anterior lower ridge is four times that of the upper ridge (50). As a consequence of residual ridge reduction, and loss of sulcus width and depth with displacement of the muscle attachment closer to the crest, the denture base can appear to have extended borders, which also causes loss of retention. The morphological changes and the reduction of residual ridges in long-term wearers of complete dentures present serious problems to clinicians when deciding how to provide adequate support, stability and retention of new dentures $(51,52)$. When the fit is not exact, the forces are not distributed over the greatest possible surface of the bone, but are concentrated on certain spots and can cause ulceration.

In the present study, mandibular dentures with long vestibular borders showed significantly more epulis fissuratum formation. Continuing reduction of the mandibular residual ridges in long-term denture wearers must have created longer mandibular denture borders over time, causing the denture borders to thrust into the underlying soft tissue and resulting in epulis fissuratum. This finding underlines the importance of yearly recalls, since the development of epulis fissuratum seems to be insidious and patients do not necessarily become aware of it.

Resorption of bone results in loss of both occlusal and rest vertical dimension $(51,52)$. The former dimension is reduced to a greater extent, thus increasing the freeway space. Inappropriate occlusal vertical dimension is another important factor that diminishes masticatory force and makes chewing a tiring activity. The present results confirmed the fact that generally, clinicians tend to prefer a relatively low occlusal vertical dimension, since this causes less discomfort (70.3\%; Table 2). Additionally, it is generally known that an excessive vertical dimension can lead to clicking of the dentures during speech or indistinct pronunciation if the patient consciously tries to hold the teeth apart to keep them from clicking. The present study found no influence of higher vertical dimension on patient satisfaction rates, probably due to the low percentage of patients who were affected (3.1\%; Table 2). Further studies focusing mainly on this issue in equal patient groups are needed before more reliable conclusions can be drawn.

Correct centric occlusion would also be expected to influence denture comfort, and thus patient satisfaction. However, the present results failed to show this, possibly because of the advanced wear of the artificial teeth, which prevented premature contact, and thus did not elicit any complaints. Additionally patients' TMJ and musculature may have adapted to the faultily acquired centric occlusion through remodeling.

This study involved patients having sought prosthodontic treatment at a university clinic, which may be regarded as a limitation because the subjects already had complaints related to their existing dentures that required professional correction or even new dentures. For these reasons, our results may have differed from those that would have been obtained from wearers of complete dentures taken from the general population. In order to draw more reliable conclusions, cross-sectional clinical audit studies from different centers involving more patients will be necessary. However, within the limitations of the present study, it can be concluded that in any given population seeking new complete dentures, the most frequently encountered complication is loss of retention, followed by ulceration (sore spots due to denture), loss or fracture of artificial teeth, and fracture of dentures. While ulceration can negatively affect patients' speech satisfaction scores, it appears that other complications do not influence patient satisfaction. Although epulis fissuratum is not a factor that elicits dissatisfaction, is seen most frequently in patients wearing mandibular dentures with extensive vestibular borders. This finding highlights the importance of yearly recalls, as the development of epulis fissuratum seems to be insidious and patients do not necessarily become aware of it.

\section{References}

1. Bilhan H, Erdogan O, Ergin S, Celik M, Ates G, Geckili O (2012) Complication rates and patient satisfaction with removable dentures. J Adv Prosthodont 4, 109-115.

2. Dorner S, Zeman F, Koller M, Lang R, Handel G, Behr M (2010) Clinical performance of complete dentures: a retrospective study. Int J Prosthodont 23, 410-417.

3. Steele JG, Treasure E, Pitts NB, Morris J, Bradnock G (2000) Total tooth loss in the United Kingdom in 1998 and implications for the future. Br Dent J 189, 598-603.

4. Basker RM, Davenport JC (2002) Prosthetic treatment of the edentulous patient. 4th ed, Blackwell, Oxford, 21-31.

5. Basker RM, Davenport JC (2002) Prosthetic treatment of the edentulous patient. 4th ed, Blackwell, Oxford, 56-71.

6. Beck CB, Bates JF, Basker RM, Gutteridge DL, Harrison 
A (1993) A survey of the dissatisfied denture patient. Eur J Prosthodont Restor Dent 2, 73-78.

7. Brunello DL, Mandikos MN (1998) Construction faults, age, gender, and relative medical health: factors associated with complaints in complete denture patients. J Prosthet Dent 79, 545-554.

8. Grant AA, Heath JR, McCord JF (1994) Complete prosthodontics: problems, diagnosis and management, C.V. Mosby, St Louis, 44-45.

9. Zarb GA, Bolender CL, Eckert S, Jacob R, Fenton A, Mericske-Stern R (2004) Prosthodontic treatment for edentulous patients: complete dentures and implant-supported prostheses. 12th ed, C.V. Mosby, St Louis, 298.

10. Jeganathan S, Payne JA (1993) Common faults in complete dentures: a review. Quintessence Int 24, 483-487.

11. Barsby MJ, Hellyer PH, Schwarz WD (1995) The qualitative assessment of complete dentures produced by commercial dental laboratories. Br Dent J 179, 51-57.

12. Spiekermann H, Donath K, Hassell T, Jovanovic S, Richter J (1995) Implantology color atlas of dental medicine, Thieme Pub Group, New York, 153-154.

13. Bergman B, Carlsson GE (1972) Review of 54 complete denture wearers. Patient's opinions 1 year after treatment. Acta Odontol Scand 30, 399-414.

14. Heyink JW, Heezen JH, Schaub RMH (1986) Dentist and patient appraisal of complete dentures in a Dutch elderly population. Community Dent Oral Epidemiol 14, 323-326.

15. van Waas MA (1990) The influence of clinical variables on patients' satisfaction with complete dentures. J Prosthet Dent 63, 307-310.

16. van Waas MA (1990) Determinants of dissatisfaction with dentures: a multiple regression analysis. J Prosthet Dent 64, 569-572.

17. Kalk W, de Baat C, Kaandorp A (1991) Comparison of patients' views and dentists' evaluations 5 years after complete denture treatment. Community Dent Oral Epidemiol 19, 213-216.

18. Salonen MA (1994) Assessment of states of dentures and interest in implant retained prosthetic treatment in 55-yearold edentulous Finns. Community Dent Oral Epidemiol 22, 130-135.

19. Langer A, Michman J, Seifert I (1961) Factors influencing satisfaction with complete dentures in geriatric patients. J Prosthet Dent 11, 1019-1031.

20. Smith M (1976) Measurement of personality traits and their relation to patient satisfaction with complete dentures. J Prosthet Dent 35, 492-503.

21. Manne S, Mehra R (1983) Accuracy of perceived treatment needs among geriatric denture wearers. Gerodontology 2, $67-71$.

22. Magnusson T (1986) Clinical judgment and patients' evaluation of complete dentures five years after treatment. A follow-up study. Swed Dent J 10, 29-35.

23. Firtell DN, Finzen FC, Holmes JB (1987) The effect of clinical remount procedures on the comfort and success of complete dentures. J Prosthet Dent 57, 53-57.
24. Jennings DE (1989) Treatment of the mandibular compromised ridge: a literature review. J Prosthet Dent 61, 575-579.

25. Jooste CH, Thomas CJ (1992) The influence of the retromylohyoid extension on mandibular complete denture stability. Int J Prosthodont 5, 34-38.

26. Kalk W, van Waas MA, Engels SE (1992) A comparison of different treatment strategies in patients with atrophic mandibles: a clinical evaluation after 6.5 years. Int J Prosthodont 5, 277-283.

27. Harper GW (1993) Posterior base repair to maximize complete denture retention. Compendium 14, 454-460.

28. Sykora O, Sutow EJ (1993) Posterior palatal seal adaptation: influence of processing technique, palate shape and immersion. J Oral Rehabil 20, 19-31.

29. Garrett NR, Kapur KK, Perez P (1996) Effects of improvements of poorly fitting dentures and new dentures on patient satisfaction. J Prosthet Dent 76, 403-413.

30. Hummel SK, Wilson MA, Marker VA, Nunn ME (2002) Quality of removable partial dentures worn by the adult U.S. population. J Prosthet Dent 88, 37-43.

31. Inoue M, John MT, Tsukasaki H, Furuyama C, Baba K (2011) Denture quality has a minimal effect on health-related quality of life in patients with removable dentures. J Oral Rehabil 38, 818-826.

32. Douglass CW, Watson AJ (2002) Future needs for fixed and removable partial dentures in the United States. J Prosthet Dent 87, 9-14.

33. Silverman MM (2001) The speaking method in measuring vertical dimension. J Prosthet Dent 85, 427-431.

34. Celenza FV (1984) The theory and clinical management of centric positions: II. Centric relation and centric relation occlusion. Int J Perio Rest Dent 4, 62-66.

35. Basker RM, Davenport JC (2002) Prosthetic treatment of the edentulous patient. 4th ed, Blackwell, Oxford, 1-21.

36. Allen F, Locker D (2002) A modified short version of the oral health impact profile for assessing health-related quality of life in edentulous adults. Int J Prosthodont 15, 446-450.

37. Zitzmann NU, Marinello CP (2006) Survey of treatmentseeking complete denture wearers concerning tooth loss, retention behavior and treatment expectations. Schweiz Monatsschr Zahnmed 116, 229-236.

38. Atwood DA (1971) Reduction of residual ridges: a major oral disease entity. J Prosthet Dent 26, 266-279.

39. Carlsson GE (1998) Clinical morbidity and sequelae of treatment with complete dentures. J Prosthet Dent 79, 17-23.

40. Hargreaves AS (1969) The prevalence of fractured dentures. A survey. Br Dent J 126, 451-455.

41. Beyli MS, von Fraunhofer JA (1981) An analysis of causes of fracture of acrylic resin dentures. J Prosthet Dent 46, 238-241.

42. Darbar UR, Huggett R, Harrison A (1994) Denture fracture - a survey. Br Dent J 176, 342-345.

43. Karacaer O, Dogan OM, Tincer T, Dogan A (2001) Reinforcement of maxillary dentures with silane-treated ultra high modulus polyethylene fibers. J Oral Sci 43, 103-107.

44. Jagger DC, Harrison A, Jandt KD (1999) The reinforcement of 
dentures. J Oral Rehabil 26, 185-194.

45. Basker RM, Davenport JC (2002) The prosthetic treatment of the edentulous patient. 4th ed, Blackwell, Oxford, 269-311.

46. Cunningham JL, Benington IC (1999) An investigation of the variables which may affect the bond between plastic teeth and denture base resin. J Dent 27, 129-135.

47. Takahashi Y, Chai J, Takahashi T, Habu T (2000) Bond strength of denture teeth to denture base resins. Int J Prosthodont 13, 59-65.

48. Geering AH, Kundert M, Kelsey CC (1993) Complete denture and overdenture prosthetics, G. Thieme Verlag, New York, 189-216.

49. Fenton AH (2004) Selecting and arranging prosthetic teeth and occlusion for the edentulous patient. In: Prosthodontic treatment for edentulous patients: complete dentures and implant-supported prostheses, 12th ed, Zarb GA, Bolender CL, Eckert SE, Fenton AH, Jacob RF, Mericske-Stern R eds, C.V. Mosby, St Louis, 298-329.

50. Douglass JB, Meader L, Kaplan A, Ellinger CW (1993) Cephalometric evaluation of the changes in patients wearing complete dentures: a 20-year study. J Prosthet Dent 69, 270-275.

51. Budtz-Jørgensen E (1997) Sequelae caused by wearing complete dentures. In: Boucher's prosthodontic treatment for edentulous patients, 11 th ed, Zarb GA, Bolender CL, Carlsson GE eds, C.V. Mosby, St Louis, 30-45.

52. Basker RM, Davenport JC (2002) The prosthetic treatment of the edentulous patient. 4th ed, Blackwell, Oxford, 260-269. 